\title{
Factors associated with patient satisfaction in teaching hospitals in Zahedan (Iran) in 2017: a two-level regression model
}

\author{
Mahnaz Khosravi ${ }^{1}$, Yunes Jahani ${ }^{2}$, Moghaddameh Mirzaee ${ }^{2}$, Abolfazl Payandeh $^{3}$, Abbas Bahrampour ${ }^{4}$
}

${ }^{1}$ M.Sc. of Biostatistics, Vice Chancellor for Treatment Affairs, Zahedan University of Medical Sciences, Zahedan, Iran

${ }^{2}$ Ph.D. of Biostatistics, Associate Professor, Modeling in Health Research Center, Institute for Futures Studies in Health, Kerman University of Medical Sciences, Kerman, Iran

${ }^{3}$ Ph.D. of Biostatistics, Assistant Professor, Health Promotion Research Center, Zahedan University of Medical Sciences, Zahedan, Iran

${ }^{4}$ Ph.D. of Biostatistics, Professor, Modeling in Health Research Center, Institute for Futures Studies in Health, Kerman University of Medical Sciences, Kerman, Iran

\section{Type of article: Original}

\begin{abstract}
Background: Since satisfaction is considered the main factor for improving the quality of healthcare organizations, patients' satisfaction from healthcare services and hospital staff is very important.

Objective: The aim of this study was to determine factors associated with patient satisfaction in teaching hospitals.

Methods: This cross-sectional study was performed on 440 patients hospitalized in teaching hospitals affiliated with Zahedan University of Medical Sciences in 2017. Patients were selected using stratified sampling from different departments of which the sample size of each department was proportional to the number of patients from each department. The Goldberg General Health Validity Questionnaire that included questions about satisfaction and mental health was completed by patients. The patients' satisfaction of the hospital was the dependent variable, and mental health, age, gender, education, occupation, type of insurance, marital status, place of residence, length of stay and number of hospitalization were independent variables. The data were analyzed by a linear two-level regression model in Stata 12.

Results: The mean age of the patients was $40.79 \pm 19.48$ years and $51.6 \%$ of them were male. The mean score of patient satisfaction (in a range of $0-20$ ) was $14.96 \pm 2.47$. Age, education, mental health, and interaction between age and mental health had significant effect on satisfaction $(p=0.003, p=0.004, p<0.001, p=0.002)$. The mean score of satisfaction in patients with elementary education was 1.74 less than that of illiterate patients, and the score of satisfaction in patients with higher education was 2.92 less than that of illiterate patients, and the mental health in low age subgroups had a significant effect on patient satisfaction. There was also significant difference in the satisfaction levels of patients between hospital departments $(p<0.001)$.

Conclusions: The satisfaction levels of patients in different departments of the hospitals varied. Also, the patients with high mental health had high satisfaction from healthcare services and hospitals.

Keywords: Patient satisfaction, Mental health, Multilevel analyses, Department, Hospital
\end{abstract}

\section{Corresponding author:}

Associate Professor Dr. Yunes Jahani, Modeling in Health Research Center, Institute for Futures Studies in Health, Kerman University of Medical Sciences, Kerman, Iran.

Tel: +98.3431325421, Fax: +98.3432114278, Email: yonesjahani@yahoo.com

Received: April, 03, 2018, Accepted: October 17, 2018, Published: November 2018

iThenticate screening: July 23, 2018, English editing: October 20, 2018, Quality control: October 22, 2018

This article has been reviewed / commented by four experts

Funding / research project approval: Kerman University of Medical Sciences (Ref: 1394.381)

Ethics approval: Kerman University of Medical Sciences (Ref: K/940441)

(C) 2018 The Authors. This is an open access article under the terms of the Creative Commons Attribution-NonCommercialNoDerivs License, which permits use and distribution in any medium, provided the original work is properly cited, the use is non-commercial and no modifications or adaptations are made. 


\section{Introduction}

Patient satisfaction is considered as an indicator for assessing and improving the quality of healthcare services including factors such as facilities for in-patient hospital services and patients' expectations (1). Patient satisfaction refers to their expectations of healthcare services delivered at healthcare centers (2). The first studies focused on the concept of patient satisfaction from the treatment process in 1950 in the United States and in 1960 in the UK $(3,4)$. In $2015,30 \%$ of the overall hospital score was based on measuring patients' experiences, resulting in a strong incentive for hospitals to provide patient-centered care (5). In some studies, it has been determined that patient satisfaction with the treatment process in our country is higher than that of other countries (6). Of course, some scholars in the interpretation of these findings mentioned the phenomenon of non-familiarity of patients with their rights (7).

Today, a greater emphasis is being placed on patients' expectations, so that the quality of healthcare services and patients' satisfaction have become the priorities of healthcare organizations, and there is an increase in the number of studies on these issues (8). According to the World Health Organization (WHO), good health is not merely the absence of disease or infirmity, but also a state of complete physical, mental, and social well-being (9). Mental health refers to a feeling of well-being, self-actualization, and potential intellectual, emotional satisfaction. People with mental health can logically deal with problems, adapt to environments, and be happy with their life (10). Various factors have an effect on patients' satisfaction. Researchers believe there is a relationship between patient satisfaction and health status (11). Patrick et al., in 1983 found that patients with a low status of health were satisfied with healthcare services but Hall et al. reported a positive relationship between patients' satisfaction and their health performance $(12,13)$. Aspects of mental health such as depression, anxiety, and social behavior were the important factors that affected the quality of life (14). Hulsbosch et al., in 2016 showed that there was a significant relationship between mental health and patient satisfaction; in other words, an improvement in patients' mental health could raise their level of satisfaction (15). Other studies in Iran showed that there was no significant relationship between satisfaction and place of residence, type of insurance, marital status or occupation, but patient satisfaction with gender, education and length of stay had a significant relationship $(16,17)$.

The aim of this study was to determine the factors associated with satisfaction of patients hospitalized in the teaching hospitals affiliated with Zahedan University of Medical Sciences using a multilevel linear model. Patients and hospital departments construct a hierarchical or multilevel structure, because the patients of each department have similar facilities like students of a school that have similar characteristics (18) or children who grow up in a family with similar physical and emotional characteristics compared to others (19). Since the majority of studies in Iran have evaluated satisfaction without considering the hierarchical structure of the data, in this study a multilevel model was used to assess the patient satisfaction, which considers the hierarchical structure of the hospital departments and patients.

\section{Material and Methods}

\subsection{Study design, place and time of the study}

This cross-sectional study was conducted on 440 patients hospitalized over 24 hours in the teaching hospitals affiliated with Zahedan University of Medical Sciences in 2017. The participants were selected from two large teaching hospitals affiliated with Zahedan University of Medical Sciences (the Ali-ebn Abitaleb and Khatamolanbia hospitals) including different departments such as general surgery, neurosurgery, internal medicine, neurology, orthopedics, obstetrics and gynecology, pediatrics, burns, CCU, PCCU, ICU. The reason for the selection these hospitals was that they are the main referral centers for patients in Sistan and Baluchestan province.

\subsection{Sampling}

\subsubsection{Sample size}

To determine the sample size, considering a correlation coefficient of 0.15 between patients' health, the main independent variable in this study, and patients' satisfaction and a significance level of 0.05 , and the statistical power of $80 \%, 355$ patients were estimated. By considering the potential dropout rate of $20 \%, 440$ patients were finally enrolled in this study.

\subsubsection{Sampling method}

From each hospital department, 20-45 patients were selected through stratified sampling and were proportional to the size of the departments. Owing to the hierarchical structure of patients and hospital departments, each department was considered a strata which the patients were the first level and the departments were the second-level. 


\subsection{Selection criteria}

Inclusion criteria were all patients who were over 10 years old. Exclusion criteria were the following: 1) Patients of the ICU department who were unable to complete the questionnaire and whose families could not be accessed; 2) Patients of burns departments who were unable to complete the questionnaire and whose families could not be accessed.

\subsection{Research tool and data collection}

Data were collected using Goldberg's General Health and a patient satisfaction Questionnaire (20). This questionnaire was used in the study of Bahrampour et al. in Iran (21). The questionnaire includes 28 questions related to the psychological status of the patients, and another 28 questions, related to the patients' satisfaction. The questionnaire consists of four parts: 1) demographic characteristics (gender, age, marital status, education, occupation, and place of residence), 2) medical factors (length of stay, admission, hospital readmission, and medical insurance type), 3) satisfaction (behavior of physicians, nurses, staff, their availability, and other services), and 4) mental health status of patients (physical symptoms, anxiety, social performance, and depression). Questions 4 and 5 were optional. The method of scoring was based on the 5-point Likert scale. The final score in satisfaction and mental health of patients was obtained by summing up the score of the related questions. The minimum score of satisfaction was 16 and the maximum was 80 and converted to a range scale of $0-20$ for easy interpretation. The mental health score was between 28 and 112 . We converted them to a range scale of $0-20$. In both variables, lower scores meant lower levels of satisfaction and mental health, and higher scores meant higher levels of satisfaction and mental health. Reliability and validity of the questionnaires were confirmed by Bahrampour et al. in 2005 (21). In this study, internal consistency, measured with the Cronbach's alpha of satisfaction and mental health were 0.88 and 0.93 respectively. Since a significant number of the patients were illiterate, the questionnaires were completed by the researcher.

\subsection{Statistical analysis}

In this study, patient satisfaction was considered as response variable and other variables as independent variables.

To determine the effective factors on patient satisfaction, a two-level regression model was fitted to the data and the following equation was obtained:

$\mathrm{y}_{\mathrm{ij}}=\mathrm{b}_{0 \mathrm{j}}+\mathrm{b}_{1 \mathrm{j}} \mathrm{x}_{\mathrm{ij}}+\varepsilon_{\mathrm{ij}}, \mathrm{b}_{0 \mathrm{j}}=\mathrm{b}_{0}+\mathrm{u}_{0 \mathrm{j}}, \mathrm{b}_{1 \mathrm{j}}=\mathrm{b}_{1}+\mathrm{u}_{1 \mathrm{j}}$

In this equation, $b_{0 \mathrm{j}}$ is the random intercept, $\mathrm{b}_{1 \mathrm{j}}$, random regression coefficient, $\varepsilon_{\mathrm{ij}}$, random error, and $\mathrm{u}_{0 \mathrm{j}}$ and $\mathrm{u}_{1 \mathrm{j}}$ are random parts of the model. Index of $j$ was defined for departments $(j=1, \ldots 17)$ and $i$ for patients $(i=1, \ldots, n j)$. In the multilevel model, a random component is usually assumed to be normally distributed with zero mean and constant variance $\sigma^{2}$. Significant $u_{0 j}$ showed the differences in the patient satisfaction level in different hospital departments and the suitability of a multilevel model for data, and significant $u_{1 j}$ showed the interaction between departments and independent variables associated with patient satisfaction. Data were analyzed by Stata 12. The statistically significant level was fixed at $\alpha=0.05$.

\subsection{Ethical considerations}

The study protocol was approved by the ethics committee of Kerman University of Medical Sciences (Ethics code No: K/940441). The study and its objectives were first explained to the patients who were assured that their information would remain confidential. Informed oral consent was obtained from all patients. Before completion of the questionnaire, the necessary information were given to the patients.

\section{Results}

In this study, 440 patients were included and the results of the study are shown in Tables 1 and 2. The mean age of patients was $40.79 \pm 19.48$ years and the mean of their length of stay was $4.21 \pm 4.41$ days. Among the patients, $51.6 \%$ were female, and $36.4 \%$ were illiterate. Most patients (55.9\%) were covered by the Health Services, and $75.2 \%$ of them were married. Only $28.6 \%$ of them were rural, and $21.6 \%$ of them had a history of hospitalization. The mean scores of patient satisfaction and mental health were $14.96 \pm 2.47$ and $14.60 \pm 2.71$, respectively. The highest score of mental health aspects was related to depression $(16.83 \pm 3.85)$ and the lowest one belonged to social performance $(12.1 \pm 2.67)$. 
Table 1. Frequency distributions of quantitative variables of patients hospitalized in the teaching hospitals affiliated with Zahedan University of Medical Sciences

\begin{tabular}{|c|c|c|c|}
\hline \multicolumn{2}{|l|}{ Variables } & $\mathrm{n}$ & $\%$ \\
\hline \multirow[t]{2}{*}{ Gender } & Male & 213 & 48.4 \\
\hline & Female & 227 & 51.6 \\
\hline \multirow[t]{3}{*}{ Education } & Illiterate & 160 & 36.4 \\
\hline & Elementary & 144 & 32.7 \\
\hline & Secondary or higher & 136 & 30.9 \\
\hline \multirow[t]{4}{*}{ Types of Insurance } & Social Insurance & 109 & 28.4 \\
\hline & Health Services & 246 & 55.9 \\
\hline & Imam Khomeini Relief Committee & 29 & 6.6 \\
\hline & Others & 56 & 12.7 \\
\hline \multirow[t]{3}{*}{ Occupation } & Employed & 200 & 45.5 \\
\hline & Unemployed & 23 & 5.2 \\
\hline & Inactive & 217 & 49.3 \\
\hline \multirow[t]{2}{*}{ Hospital } & Ali-ebn Abitaleb & 250 & 56.8 \\
\hline & Khatamolanbia & 190 & 43.2 \\
\hline \multirow[t]{2}{*}{ Marital Status } & Single & 109 & 24.8 \\
\hline & Married & 331 & 75.2 \\
\hline \multirow[t]{2}{*}{ Place of Residence } & Urban & 314 & 71.4 \\
\hline & Rural & 126 & 28.6 \\
\hline \multirow[t]{2}{*}{ History of Hospitalization } & Yes & 95 & 21.6 \\
\hline & No & 345 & 78.4 \\
\hline
\end{tabular}

Table 2. Descriptive statistics of qualitative variables of patients hospitalized in the teaching hospitals affiliated with Zahedan University of Medical Sciences

\begin{tabular}{|l|l|l|l|l|l|}
\hline Variables & Minimum & Maximum & Mean & SD \\
\hline Age (year) & 10 & 89 & 40.79 & 19.48 \\
\hline Number of hospitalization & 1 & 10 & 1.42 & 1.07 \\
\hline Length of Stay (day) & 1 & 45 & 4.21 & 4.41 \\
\hline \multicolumn{2}{|l|}{ Mental health (score) } & 3.10 & 19.76 & 14.60 & 2.71 \\
\hline \multirow{3}{*}{ Aspects of mental health } & Physical Symptoms & 0.95 & 20 & 14.40 & 3.28 \\
\cline { 2 - 6 } & Anxiety & 2.86 & 20 & 15.12 & 3.79 \\
\cline { 2 - 6 } & Social performance & 0.95 & 20 & 12.1 & 2.67 \\
\cline { 2 - 6 } & Depression & 0 & 20 & 16.83 & 3.85 \\
\hline \multicolumn{1}{|l|}{ Patients' satisfaction } & & 5.31 & 20 & 14.96 & 2.47 \\
\hline
\end{tabular}

SD: Standard deviation

The results of fitting univariate and multiple two-level regression models to data have been shown in Tables 3 and 4. According to Table 3, in the univariate model, the variables education, age, number of hospitalization, and mental health were statistically significant at the level $\alpha=0.2$ and as important variables were put in the multiple model. As shown in the last column of Table 3, a significant difference from zero in variance of patient satisfaction in different departments was reported $(\mathrm{p}<0.001)$ and patient satisfaction in different departments was different. In the multiple model, the variables education $(p=0.004)$, age $(p=0.003)$, mental health $(p<0.001)$, and the interaction between age and mental health $(\mathrm{p}=0.002)$ were statistically significant. The random coefficient of variables was not significant, indicating that all the independent variables had a similar effect on patient satisfaction in all departments and there was no interaction between departments and the independent variables related to patient satisfaction. The final multiple model was described as follows:

$\mathrm{E}\left(\mathrm{Y}_{\mathrm{ij}}\right)=45.49+1.36$ (mental health) -1.74 (elementary education $)-2.92$ (secondary or higher education $)+0.33$ (age) -0.02 (interaction between age and mental health).

According to Table 4 and the final model, the patient satisfaction of those with elementary education was 1.74 less than that of illiterate patients, and the score of satisfaction in patients with secondary or higher education was 2.92 less than that of illiterate patients. Owing to an interaction between age and mental health and for a better 
description, the age and mental health were grouped and the effect of age on satisfaction in subgroups of mental health and the effect of mental health on the satisfaction in subgroups of age were investigated. It was revealed that age had no effect on patient satisfaction in any of the subgroups of mental health but mental health in lower age ranges had significant effect on satisfaction (Table 5). In the 10-18 years age group, an increase in the score of mental health increased the satisfaction scores as much as 0.87 , in the 18-38 years age group, 0.87 and in the 35-60 years age group, 0.59 . In the over-60 age group, mental health had no significant effect on patient satisfaction. The studied departments were different according to patient satisfaction $(\mathrm{p}<0.001)$.

Table 3. Fitting a univariate two-level model with random intercepts to satisfaction of patients hospitalized in the hospitals affiliated with Zahedan University of Medical Sciences

\begin{tabular}{|c|c|c|c|c|}
\hline \multicolumn{2}{|l|}{ Variables } & $\beta(95 \% \mathrm{CI})$ & p-value & $\operatorname{var}\left(\mathrm{u}_{0 \mathrm{j}}\right)(95 \% \mathrm{CI})$ \\
\hline Gender & Female & $0.57(-0.94,2.08)$ & 0.46 & $2.23(0.51,9.66)$ \\
\hline \multicolumn{2}{|l|}{ Age } & $0.31(-0.01,0.07)$ & $0.13 *$ & $1.91(0.38 .9 .52)$ \\
\hline \multirow[t]{2}{*}{ Occupation } & Unemployed & $0.81(-2.56,4.18)$ & 0.52 & $2.40(0.58,9.99)$ \\
\hline & Inactive & $0.89(-0.66,2.45)$ & & \\
\hline Hospital & Khatamolanbia & $1.01(-1.02,3.02)$ & 0.33 & $1.94(0.41,9.28)$ \\
\hline Marital status & Married & $1.03(-0.74,2.81)$ & 0.25 & $2.13(0.47,9.55)$ \\
\hline Place of residence & Rural & $0.94(-0.69,2.56)$ & 0.26 & $2.32(0.55,9.77)$ \\
\hline \multirow[t]{3}{*}{ Type of medical Insurance } & Health Services & $0.75(-1.02,2.51)$ & \multirow[t]{3}{*}{0.54} & $2.13(0.47,9.52)$ \\
\hline & $\begin{array}{l}\text { Imam Khomeini Relief } \\
\text { Committee }\end{array}$ & $2.23(-1.01,5.46)$ & & \\
\hline & Others & $1.16(-1.37,3.69)$ & & \\
\hline History of hospitalization & No & $0.35(-1.44,2.15)$ & 0.69 & $2.20(0.5,9.6)$ \\
\hline \multirow[t]{2}{*}{ Education } & Elementary & $-1.47(-3.26,-0.31)$ & \multirow[t]{2}{*}{$0.02 *$} & $2.4(0.57,10.03)$ \\
\hline & Secondary or higher & $-2.54(-4.33,-0.74)$ & & \\
\hline \multicolumn{2}{|l|}{ Length of stay } & $-0.10(-0.27,0.07)$ & 0.24 & $2.07(0.45,9.44)$ \\
\hline \multicolumn{2}{|l|}{ Number of hospitalization } & $-0.46(-1.15,0.23)$ & $0.19 *$ & $2.35(0.56,9.80)$ \\
\hline \multicolumn{2}{|l|}{ Mental health } & $0.11(0.49,0.18)$ & $0.0006^{*}$ & $1.56(0.27,9.14)$ \\
\hline
\end{tabular}

* Significant at level $\alpha=0.2$ by likelihood ratio test and were as important variables.

Table 4. Fitting the multiple two-level model to satisfaction of patients hospitalized in the hospitals affiliated with Zahedan University of Medical Sciences

\begin{tabular}{|l|l|l|l|}
\hline Variables & $\beta(95 \%$ CI $)$ & $p$-value \\
\hline Education & Elementary & $-1.74(-3.66,0.2)$ & 0.074 \\
\cline { 2 - 4 } & Secondary or higher & $-2.92(-4.9,-0.92)$ & $0.004^{*}$ \\
\hline Age & $0.33(0.11,0.54)$ & $0.003^{*}$ \\
\hline Mental health & $1.36(0.77,1.95)$ & $<0.0001^{*}$ \\
\hline Interaction between age and mental health & $-0.02(-0.04,-0.01)$ & $0.002^{*}$ \\
\hline Random intercept variance & $2.14(0.46,9.90)$ & $<0.0001^{*}$ \\
\hline
\end{tabular}

* Significant variables in the multiple model

Table 5. The effect of mental health on patients' satisfaction in different age groups and the effect of age on satisfaction in mental health subgroups (adjusted for education)

\begin{tabular}{|l|l|l|l|}
\hline \multicolumn{2}{|l|}{ Variables } & $\beta(95 \% \mathrm{CI})$ & P-value \\
\hline Age (year) & $10-18$ & $0.87(0.14,1.59)$ & 0.02 \\
\cline { 2 - 4 } & $18-35$ & $0.87(0.44,1.3)$ & $<0.00001$ \\
\cline { 2 - 4 } & $35-60$ & $0.59(0.11,1.06)$ & 0.015 \\
\cline { 2 - 4 } & $>60$ & $-0.37(-0.99,0.24)$ & 0.235 \\
\hline Mental health & $0-10$ & $-1.18(-3.94,1.58)$ & 0.4 \\
\cline { 2 - 4 } & $10-15$ & $0.11(-0.69,0.91)$ & 0.784 \\
\cline { 2 - 4 } & $15-20$ & $0.88(-0.08,1.85)$ & 0.074 \\
\hline
\end{tabular}




\section{Discussion}

Patient satisfaction is considered as a key factor to evaluate the performance of healthcare organizations, generally done to predict patients' expectations of healthcare services. To improve hospital performance, the quality of healthcare services and, subsequently, patients' satisfaction should be improved (22). Patients' satisfaction with healthcare services can help them to trust the healthcare systems and, ultimately, accelerate patients' recovery. Therefore, the concept of patient satisfaction is of great importance (23).

From the dimensions of mental health, one can mention anxiety and depression (14). Anxiety is one of the most common psychiatric which is a feeling of worry, nervousness, or unease about a number of events and activities with uncertain outcome $(24,25)$. Depression is one of the most common neurological and psychiatric diseases, defined as a sick person's sadness and emotional changes (26). In this study, anxiety and depression in patients was acceptable, so the status of their mental health was suitable and had significant effect on patient satisfaction. Patients with lower mental health problems had higher satisfaction from healthcare services. Improving the mental health of patients during hospitalization can increase the satisfaction therefore, communication between patients and hospital staff will increase satisfaction.

Multilevel models are the extension of linear models. They are commonly used to analyze data with hierarchical structure or stratified sampling (27). In this study, a two-level regression model was used to evaluate the factors influencing satisfaction of patients hospitalized in the teaching hospitals affiliated with Zahedan University of Medical Sciences. According to the obtained results, age, education, mental health, and interaction between mental health and age in the final model (multiple) had significant effect on patient satisfaction. There were also significant differences in patients' satisfaction levels in different hospital departments, possibly due to differences in the facilities and personnel of the different departments.

Daniel et al. performed several studies on patient satisfaction and showed that the satisfaction of male patients was more than that of females, while, in another study, the satisfaction of female patients was reported to be more than that of males. Other studies reported no significant relationship between gender and satisfaction (28), which is consistent with this study. These inconsistencies can be due to the fact that some hospitals had gender-based departments, while others, especially those included in this study, had no such departments and patients used similar facilities. It, therefore, seems logical that patients reported similar levels of satisfaction. In the study by Daniel et al., no significant relationship was found between age and patient satisfaction. However, another study reported a significant relationship between age and patient satisfaction and patients with higher age had a higher satisfaction (28). In this study, age also had an effect on patient satisfaction and the inclusion of an age range of 10-89 years led to a wide range of age groups being investigated, and studies that reported age to be an insignificant factor probably selected a narrow age range or special age groups. Some of studies reported a significant relationship between education and patient satisfaction $(21,22,29)$, which was consistent with our results. In this study, patients with higher education had lower satisfaction. Maybe, these patients had high expectations of healthcare services and, therefore, their satisfaction of healthcare services reduced. It is better to consider the expectations and viewpoints of patients with higher education about healthcare services, and hospital management should aim to execute and improve them.

In the cross-sectional study of You et al., performed on patients and personnel of hospitals in China, a direct relationship between health status of patients and satisfaction was reported and $54 \%$ of patients were satisfied with the health services (30). In a study by Sack et al., $66.3 \%$ of the patients were satisfied with the hospital where they had been admitted and recommended it to others (31). In this study, approximately $75 \%$ of the patients (with a mean score of 14.96 out of 20) were satisfied with healthcare services. This high level of satisfaction could be due to the type of hospitals, since the ones selected for this study were public teaching hospitals, which delivered healthcare services with high quality and at low costs to the patients. Therefore, the type of hospital had a considerable impact on patient satisfaction.

\section{Limitations}

Considering the fact that the study population was hospitalized patients, some of them were inadequate due to their lack of cooperation. Also, many questions of the questionnaire in some cases caused patients' fatigue and led to reduced accountability accuracy. 


\section{Conclusions}

According to the obtained results, age, education, mental health, and interaction between mental health and age in the final model (multiple) had significant effect on patient satisfaction. Interaction between mental health and age means that, in age ranges lower than 60 years, an increase in the mental health of patients increased their satisfaction but in age ranges over 60 years there was no relationship. A supplementary study in the whole of Sistan and Baluchestan province, particularly the cities and non-affiliated hospitals of Zahedan University of Medical Sciences, can be a suitable route for future research in this subject through a multi-level approach.

\section{Acknowledgments:}

This study was a part of MSc thesis supported by Kerman University of Medical Sciences (Ref: 1394.381). We would like to express our gratitude to all personnel and patients of the teaching hospitals in Zahedan who completed the questionnaire and helped in doing this study. This study was funded by Kerman University of Medical Sciences.

\section{Conflict of Interest:}

There is no conflict of interest to be declared.

\section{Authors' contributions:}

All authors contributed to this project and article equally. All authors read and approved the final manuscript.

\section{References:}

1) Singh A, Dutta A, Sood J. Influence of multi-level anaesthesia care and patient profile on perioperative patient satisfaction in short-stay surgical inpatients: A preliminary study. Indian Journal of Anaesthesia. 2007; 51(2): 106-10.

2) Zahedi S, Mehri K. Comparative Study of The Patient Satisfaction In Vali-Asr and Amir-Aalam Hospitals Based on Pivotal Core Peripheral (PCP) Model. Iran Journal of Nursing. 2009; 22(61): 42-50.

3) Lin B, Kelly E. Methodological issues in patient satisfaction surveys. International Journal of Health Care Quality Assurance. 1995; 8(6): 32-7. doi: 10.1108/09526869510098840. PMID: 10165404.

4) Batchelor C, Owens DJ, Read M, Bloor M. Patient satisfaction studies: methodology, management and consumer evaluation. International journal of health care quality assurance. 1994; 7(7): 22-30. doi: 10.1108/09526869410074720. PMID: 10140849.

5) Sacks GD, Lawson EH, Dawes AJ, Russell MM, Maggard-Gibbons M, Zingmond DS, et al. Relationship between hospital performance on a patient satisfaction survey and surgical quality. JAMA surgery. 2015; 150(9): 858-64. doi: 10.1001/jamasurg.2015.1108, PMID: 26108091.

6) Silverman J, Kurtz S, Draper J. Skills for communicating with patients: CRC Press; 2016.

7) Zamani A, Shams B, Moazzam E. Communication skills training for physicians as a strategy for enhancing patients satisfaction: a model for continuing education. Iranian Journal of Medical Education. 2004; 4(1): $15-22$.

8) Ghods A, Mohammadi E, Vanaki Z, Kazemnezhad A. The meaning of patient satisfaction from nurses: A qualitative study. Iranian Journal of Medical Ethics and History. 2010; 4(1): 47-61.

9) Rahimi G. World Health Organization (WHO). Journal of the Islamic Republic of Iran. 2010; 5(1): 53-6.

10) Bajestani HS, Etemadi A, Ahmadi K. A comparison of the effectiveness of Adlerian counseling and cognitive reconstruction based on an allegory of student mental health. International Journal of Behavioral Sciences. 2012; 6(3): 237-43.

11) Larson CO, Nelson EC, Gustafson D, Batalden PB. The relationship between meeting patients' information needs and their satisfaction with hospital care and general health status outcomes. International Journal for Quality in Health Care. 1996; 8(5): 447-56. doi: 10.1093/intqhc/8.5.447. PMID: 9117198.

12) Patrick DL, Scrivens E, Charlton JR. Disability and patient satisfaction with medical care. Medical Care. 1983; 21(11): 1062-75. PMID: 6228699.

13) Hall JA, Feldstein M, Fretwell MD, Rowe JW, Epstein AM. Older patients' health status and satisfaction with medical care in an HMO population. Medical care. 1990; 28(3): 261 -70. PMID: 2314135.

14) Ahmadi-shooli P, Feily A, Behzadipour S. The Effect of Mindfulness-based Cognitive Therapy on the Mental Health of Female Patients Suffering from Multiple Sclerosis. SSU_Journals. 2016; 23(10): 9891000 .

15) Hulsbosch AM, Nugter MA, Tamis P, Kroon H. Videoconferencing in a mental health service in The Netherlands: A randomized controlled trial on patient satisfaction and clinical outcomes for outpatients 
with severe mental illness. Journal of telemedicine and telecare. 2017; 23(5): 513-520. doi: 10.1177/1357633X16650096. PMID: 27236703.

16) Yazdani Charati J, Nikpour A, Nazar I. Patients satisfaction Level from Services Provided in Sari Tooba Clinic and Associated Factors Using Hotelling's T2. Journal of Mazandaran University of Medical Sciences. 2016; 25(132): 210-8.

17) Kazemeini S, Mohammadi F, Owlia F. Evaluation of Satisfication Rate of Patients Admitted to Yazd Shaheed Sadoughi BurnHospital in First Nine Months of the year 2011. Toloo-E-Behdasht. 2013; 11(4): 91-102.

18) Twisk JW. Applied multilevel analysis: a practical guide for medical researchers. Cambridge University Press; 2006. doi: 10.1017/CBO9780511610806.

19) Gholami FM, Kazemnejad A, Zayeri F, Rowzati M. Application of three level modeling in analysis of longitudinal blood pressure data of occupational center of Isfahan's Mobarakeh steel company during years 2003 until 2009. Journal of North Khorasan University of Medical Sciences. 2011; 3: 103-113, doi: 10.29252/jnkums.3.5.S5.103.

20) Goldberg RJ, Greenwood JC, Taintor Z. Alpha conditioning as an adjunct treatment for drug dependence: Part I. International Journal of the Addictions. 1976; 11(6): 1085-9. PMID: 1025032.

21) Bahrampour A, Zolala F. Patient satisfaction and related factors in Kerman hospitals. Eastern Mediterranean Health journal. 2005; 11(5): 905-12. PMID: 16761660.

22) Péfoyo AJK, Wodchis WP. Organizational performance impacting patient satisfaction in Ontario hospitals: a multilevel analysis. BMC research notes. 2013; 6(1):509. doi: 10.1186/1756-0500-6-509.

23) Shakerinia I. Physician-patient relationship and patient's satisfaction. Iranian Journal of Medical Ethics and History of Medicine. 2009; 2(3): 9-16

24) Khadem H, Mozafari M, Yousefi A, Hashemabad BG. The relationship between spiritual health and mental health in students of Ferdowsi University of Mashhad. History of Medicine Journal (Quarterly). 2016; 7(25): 33-50.

25) Smaeili AM, Hajebi M, Hefazi A, Rad Goudarzi R, Rahimi Movaghar ASV, Motavallian SA. Thirty-first Annual Congress of Iranian Psychiatric Association. Tehran. Tehran: Milad Hospital. 2014: 1-10.

26) Ibrahim AK, Kelly SJ, Adams CE, Glazebrook C. A systematic review of studies of depression prevalence in university students. Journal of psychiatric research. 2013;47(3): 391-400. doi: 10.1016/j.jpsychires.2012.11.015. PMID: 23260171.

27) Gholami Fesharaki M, Kazemnejad A, Zayeri F, Sanati J, Akbari H. Using Bayesian Multilevel Modeling for Determining the Relationship between Shift work and Blood Pressure during a Retrospective longitudinal Study. Iranian Journal of Epidemiology. 2013; 8(4): 1-8.

28) Daniel I. The relationship between nurse staffing and patient satisfaction in emergency departments. University of Toronto; 2012.

29) Salmanian B, Mohammad Ebrahimi Z, Rovshan B, Babamahmoodi F. Verbal structural impact of doctor and patient on the patient satisfaction. Language Research. 2016; 8(20): 1.

30) You Lm, Aiken LH, Sloane DM, Liu K, He G-p, Hu Y, et al. Hospital nursing, care quality, and patient satisfaction: cross-sectional surveys of nurses and patients in hospitals in China and Europe. International journal of nursing studies. 2013; 50(2): 154-61. doi: 10.1016/j.ijnurstu.2012.05.003. PMID: 22658468.

31) Sack C, Scherag A, Lütkes P, Günther W, Jöckel K-H, Holtmann G. Is there an association between hospital accreditation and patient satisfaction with hospital care? A survey of 37000 patients treated by 73 hospitals. International Journal for Quality in Health Care. 2011; 23(3): 278-83. doi: 10.1093/intqhe/mzr011. PMID: 21515636. 